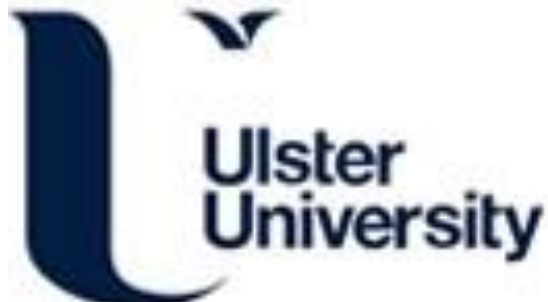

\section{Study on the Performance and Optimization of a Scroll Expander Driven by Compressed Air}

Zhang, X., Xu, Y., Xu, J., Sheng, Y., Zuo, Z., Liu, J., Chen, H., Wang, Y., \& Huang, Y. (2017). Study on the Performance and Optimization of a Scroll Expander Driven by Compressed Air. Applied Energy, 186, $347-358$. https://doi.org/10.1016/j.apenergy.2016.06.004

Link to publication record in Ulster University Research Portal

\section{Published in:}

Applied Energy

Publication Status:

Published (in print/issue): 01/01/2017

DOI:

10.1016/j.apenergy.2016.06.004

\section{Document Version}

Publisher's PDF, also known as Version of record

\section{General rights}

Copyright for the publications made accessible via Ulster University's Research Portal is retained by the author(s) and / or other copyright owners and it is a condition of accessing these publications that users recognise and abide by the legal requirements associated with these rights.

\section{Take down policy}

The Research Portal is Ulster University's institutional repository that provides access to Ulster's research outputs. Every effort has been made to ensure that content in the Research Portal does not infringe any person's rights, or applicable UK laws. If you discover content in the Research Portal that you believe breaches copyright or violates any law, please contact pure-support@ulster.ac.uk. 


\title{
Study on the performance and optimization of a scroll expander driven by compressed air
}

\author{
Xinjing Zhang ${ }^{a}$, Yujie $\mathrm{Xu}^{\mathrm{a}}$, Jian $\mathrm{Xu}^{\mathrm{a}}$, Yong Sheng ${ }^{\mathrm{a}}$, Zhitao Zuo ${ }^{\mathrm{a}}$, Jimin Liu ${ }^{\mathrm{b}}$, Haisheng Chen ${ }^{\mathrm{a}, *}$, \\ Yaodong Wang ${ }^{\mathrm{c}}$, Ye Huang ${ }^{\mathrm{d}}$ \\ a Institute of Engineering Thermophysics, Chinese Academy of Sciences, 100190 Beijing, China \\ ${ }^{\mathrm{b}}$ Ao Lung Electric Machinery Development Co. Ltd, Macao \\ 'Sir Joseph Swan Centre for Energy Research, Newcastle University, Newcastle NE1 7RU, UK \\ ${ }^{\mathrm{d}}$ School of the Built Environment, University of Ulster, Newtownabbey BT37 OQB, UK
}

\section{H I G H L I G H T S}

- Both experimental and numerical studies on a scroll expander were carried out.

- Detailed working characteristics and efficiency loss mechanism were elaborated.

- The optimal pressure ratio for a scroll expander was revealed.

- The effect of the inlet temperature and geometry parameters on the design was examined.

\section{A R T I C L E I N F O}

\section{Article history:}

Received 30 January 2016

Received in revised form 3 June 2016

Accepted 6 June 2016

Available online 16 June 2016

\section{Keywords:}

Scroll expander

Experiment

Simulation

Optimization

\begin{abstract}
A B S T R A C T
The scroll expander has been widely studied in various energy systems for power generation and refrigeration. An experimental study of a scroll expander is carried out to examine its performance. Meanwhile, a quasi-dimensional numerical modelling is presented for simulating the working process of a scroll expander, which is verified by the experimental results. The numerical model is then used to simulate the internal flow parameters to get a full understanding of working characteristics of the expander. An optimization analysis is further conducted to examine the effect of major parameters, such as working pressure ratio, air inlet temperature, clearance size and scroll vane height to pitch ratio. The results indicate that there is an optimal pressure ratio for a scroll expander, which is between 3 and 4 for the studied expander. The change of the air inlet temperature does not affect the power generation. However, the expander volumetric and isentropic efficiencies decrease along with the increment of the inlet temperature. The clearance and vane height to scroll pitch ratio also have significant impacts on the expander working performance. The efficiency and power output of the expander should be both considered when determining expander parameters of working pressure ratio, clearance size and scroll vane height to pitch ratio for designing a scroll expander.
\end{abstract}

(c) 2016 Elsevier Ltd. All rights reserved.

\section{Introduction}

Scroll expander is a volumetric machine which has a wide working range in terms of its working pressure, rotational speed and power output. It could extract mechanical power from various gas including organic gas, compressed air etc. to generate power. It has advantages of few moving parts, little vibration, low noise and simple structure. Moreover, the scroll machine of compressor is a well acknowledged technology that has been extensively applied in refrigeration and air-conditioning industry [1-3].

\footnotetext{
* Corresponding author.

E-mail address: chen_hs@iet.cn (H. Chen).
}

The scroll expander is broadly exploited in the studies of low carbon cycles, such as Organic Rankine Cycle (ORC), refrigeration cycle, $\mathrm{CO}_{2}$ cycle, small scale Compressed Air Energy Storage system (CAES) [4-9]. As indicated in Ref. [3], the scroll expander rather than turbine expanders was more suitable for small-scale power units. The prototypes include hermetic scroll expander, semihermetic scroll expander, open-drive expander and some novel types. Its pressure ratio was from 1.25 to 10 generally, rotation speed was from $250 \mathrm{rpm}$ to $5000 \mathrm{rpm}$, shaft power was from several hundreds watts to $10 \mathrm{~kW}$ and efficiency was from $10 \%$ to 80\%. A scroll expander was considered as a power generation device in a bottoming ORC for a small gas turbine $(100 \mathrm{~kW})$ in 


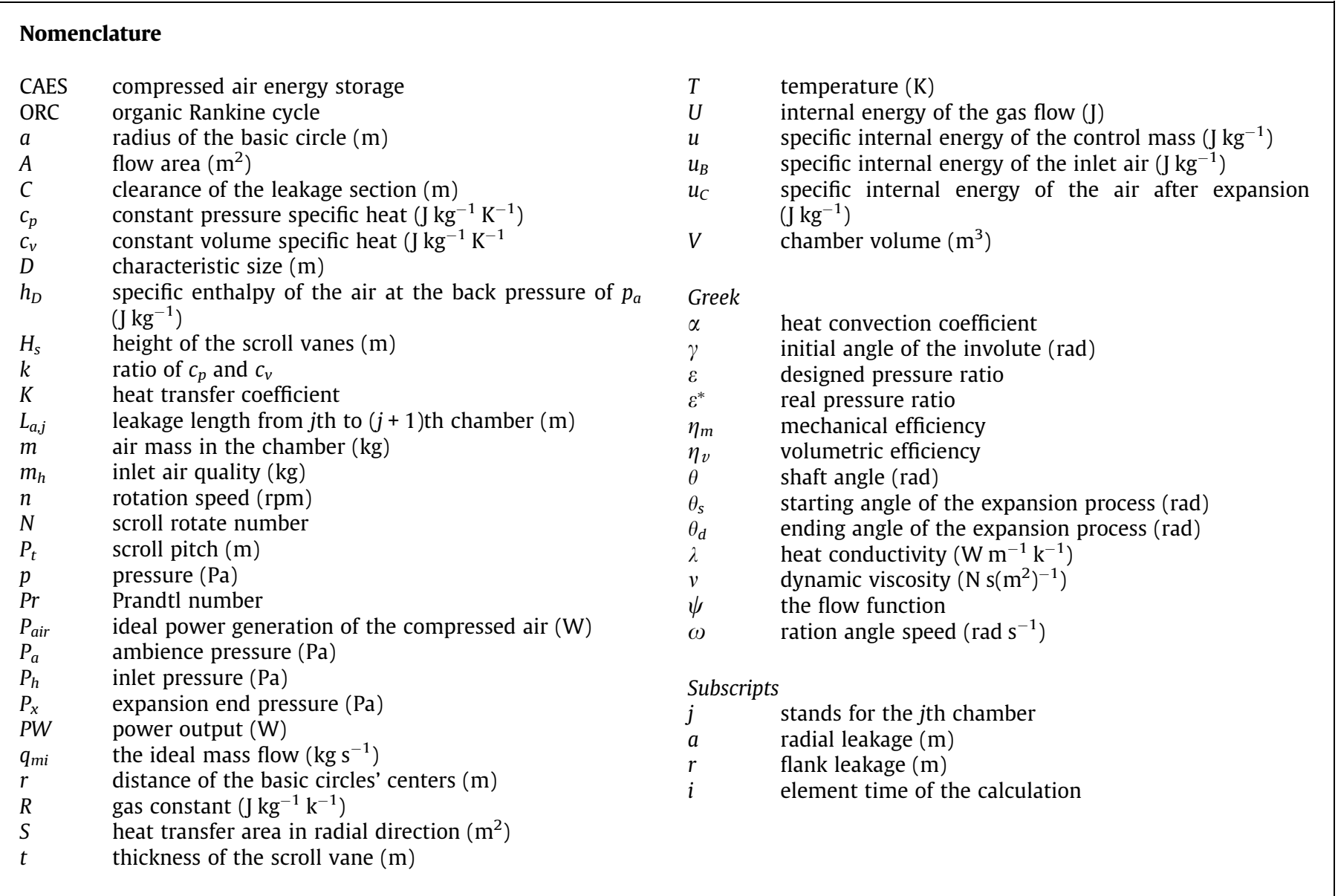

Ref. [10]. The scroll machines could represent a valid alternative to turbines for cycles fed by refrigerants such as R245fa, isopentane or isobutene. A scroll expander engaged in the heat recovery from an internal combustion engine could improve the total power output from $18 \mathrm{~kW}$ to $19 \mathrm{~kW}$ theoretically with two cases' study and the efficiency would increase from $33.7 \%$ to $35.6 \%$. This had to be regarded as an interesting value, because of the small scale of the engine [5]. Zhou et al. conducted an ORC experimental study of a heat recovery system from low-temperature flue gas $\left(90-220^{\circ} \mathrm{C}\right)$. A scroll expander was used to produce work with the working fluid of R123. Through the scroll expander, a net output power of $645 \mathrm{~W}$ was obtained, and the cycle efficiency and heat recovery efficiency were $8.5 \%$ and $22 \%$, respectively [11]. When the scroll expander was applied in a solar system, it was capable to produce $1 \mathrm{~kW}$ electric power and about $10 \mathrm{~kW}$ heat utilizing a solar thermal collector of about $20 \mathrm{~m}^{2}$ [5]. An experimental study of ORC based on scroll expander was carried out by Quoilin [12]. Its optimal results show that the systematic efficiency could be increased from 5.1\% to $9.9 \%$. A novel combination of the chemisorption cycle and the scroll expander for refrigeration and power cogeneration was for the first time investigated with numerical simulation model in Ref. [13]. The results showed that the expander power output could reach $1 \mathrm{~kW}$ theoretically under operating conditions of $170^{\circ} \mathrm{C}$ inlet temperature and $0.01 \mathrm{~kg} / \mathrm{s}$ flow rate of the ammonia vapour. The expander efficiency could be as high as $74 \%$. It also indicated that this system potentially addressed all the energy, environmental and economic issues which had been encountered by the conventional refrigeration and power generation technologies [13]. Sun et al. [14] proposed an integration of a wind turbine system and a CAES system at a few kWs scale, in which the scroll expander is utilized as the power generation device. A complete dynamic mathematical model of the hybrid system was developed, and a prototype system was built and installed in the research lab for verifying the design idea. The system test results indicated that the efficiency can be up to 55\% under a well-controlled operation condition. The findings have provided essential evidences and information for the next stage of research which will lead to the hybrid system with improved efficiency and reliability [14]. Researchers have also developed theoretical modelling for predicting and improving the scroll machine's performance. Mathematical models using thermodynamic laws were developed, which were derived with the different specific involute initial angles based on a scroll compressor. The model's main outputs were the mass flow rate, the discharge temperature and the compression work input $[15,16]$. Wang et al. [17] developed a general geometrical model based on discretional involute initial angles. This model was not restricted by involute initial angle and includes all the suction, compression and discharge periods in a subsection function manner, which provided a base for simulation of the scroll compressor and dynamic visualization of the work process of the scroll compressor [17]. As the leakage was one of the key factors influencing the scroll machine working process, an isentropic compressible nozzle flow model was commonly adopted to simulate both flank and radial leakage flows $[3,18]$. Empirical and semiempirical models were also developed based on the experimental results. The eight parameters of the semi-empirical simulation model of the expander have been identified. The model, with its parameters identified, predicted the mass flow rate, the shaft power and the exhaust temperature with a good accuracy [2]. Computational Fluid Dynamics (CFD) has been applied for the simulation of the scroll machine [19] by using dynamic mesh, which could offer a visual understanding of the inner flow characteristics. 
But it needed more work to simulate the friction (fluid-structure interaction) and multiphase flow.

Although much attention has been paid to the scroll expander, the previous work is mainly focused on its application such as the ORC and its entire performance such as power output, expander and cycle efficiencies. Rare research could be found on the study of its own performance under various conditions of rotation speed, pressure ratio, inlet temperature and structure geometries. In this study, both experimental and numerical work is presented. The experimental setup is constructed and one scroll expander is tested. A numerical model is developed to investigate the scroll expander in details, which is validated by the experimental results. Thereafter, the performance analysis and optimization are conducted for evaluating the effect of pressure ratio, air inlet temperature, clearance size and its vane height to scroll pitch ratio.

\section{Scroll expander}

Fig. 1 shows a three-dimensional (3-D) diagram of a scroll expander. It consists of two identical spiral elements - a fixed scroll and an orbiting scroll which are assembled at a relative angle of $180^{\circ}$. The scroll expander profile is a circle involute. The working process of scroll expander includes three processes: suction, expansion and discharge. The expander operational cycle can be explained as shown in Fig. 2: (i) the pressurized air enters the scroll center, (ii) this high pressure air pushes the scroll vanes and drives the orbiting scroll move around the center, (iii) the air expands from the center to the outer chambers, and (iv) finally, the air is discharged through the exhaust port. The torque is generated though the orbiting scroll movement.

Fig. 3 shows the basic parameters of circle involute that establish the scroll expander, which are elaborated in Table 1.

As the flow with high pressure enters the scroll expander, the main flow expands directly to a larger volume. Meanwhile, some flow leaks from the center to the adjacent chambers because of the pressure difference, which occurs in two ways, flank leakage and radial leakage as shown in Fig. 2.

\section{Methodology}

A scroll expander is designed and tested. While a quasidimensional model is developed to simulate the working process of the scroll expander. The expansion chamber is considered as the control volume to calculate the gas flow feature. The experimental results are used to validate the accuracy of the mathematic model. Furthermore, a detailed optimization analysis is carried out in this paper.

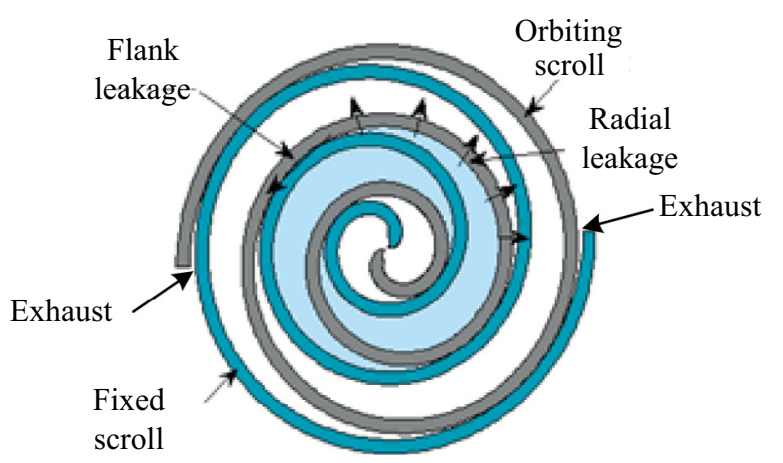

Fig. 2. Schematic diagram of the scrolls and its gas leakages inside the expander.
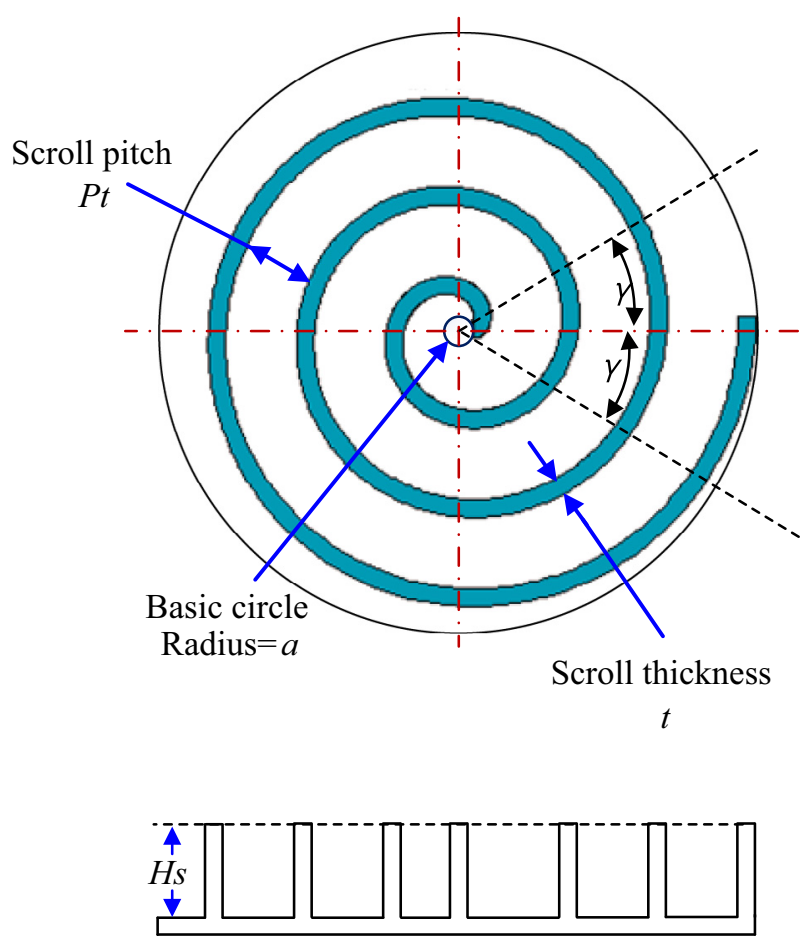

Fig. 3. Geometric parameters of a scroll expander.

\subsection{Experimental system}

The scroll expander test system is assembled to examine its performance and to validate the simulation model as mentioned

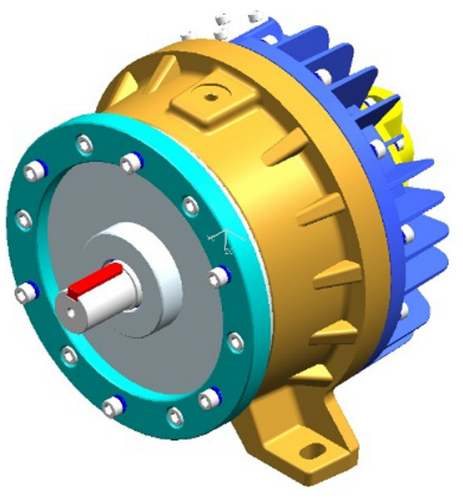

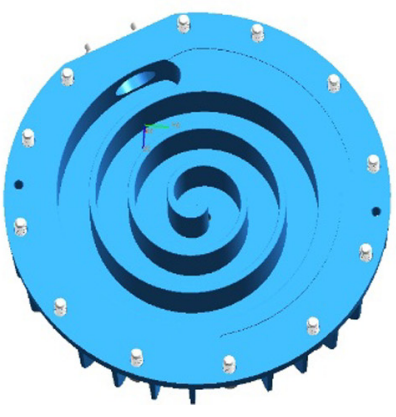

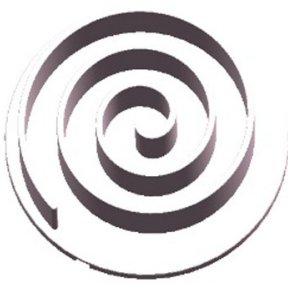

Fig. 1. Scroll expander and its scrolls. 
Table 1

Basic parameters of the scroll expander.

$\begin{aligned} & \text { Radius of the basic circle, } a \\ & \text { Height of the scroll vanes, } H_{s} \\ & \text { Scroll pitch, } P_{t}=2 \pi a\end{aligned}$
$\begin{aligned} & \text { Scroll rotate number, } N \\ & \text { Starting angle of the expansion process, } \theta_{s} \\ & \text { Ending angle of the expansion process, } \\ & \theta_{d}=2 \pi(N-1)\end{aligned}$
$\begin{aligned} & \text { Initial angle of the involute, } \gamma \\ & \text { Distance of the basic circles' centers, } r \\ & t=2 \gamma a\end{aligned}$

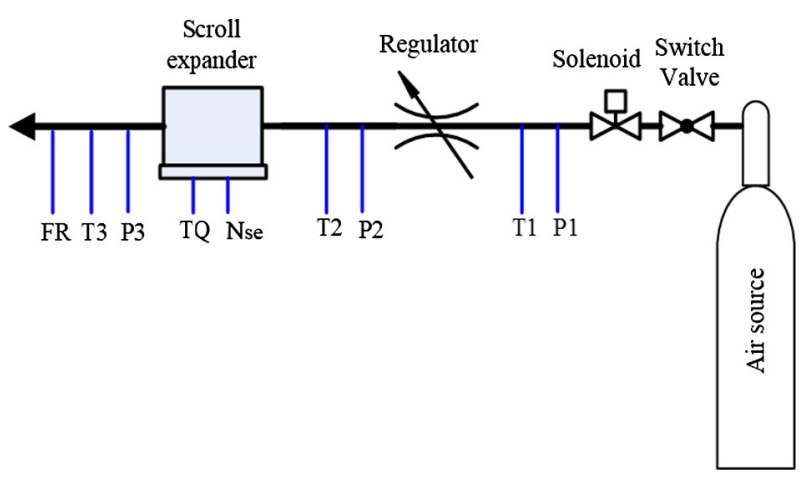

Fig. 4. Schematic diagram of the scroll expander experimental setup.

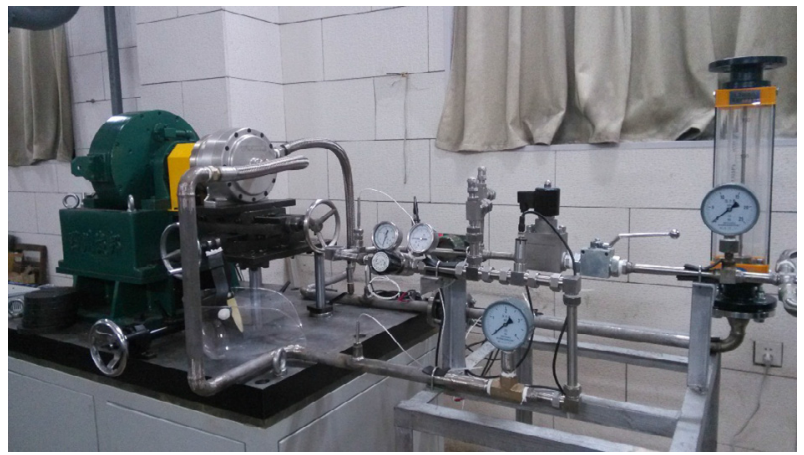

Fig. 5. Experimental setup.

below. As shown in Fig. 4, the setup consists of a high pressure air source, a switch valve, a solenoid valve, a regulator valve, the testing expander, an electric eddy current dynamometer (torque - TQ, speed $-\mathrm{N}_{\mathrm{se}}$ ), a flow meter (FR) and some pressure and temperature sensors (T, P). Fig. 5 displays the image of the experimental setup. The regulator valve could adjust the inlet air pressure. And the dynamometer is utilized to absorb the shaft power produced by the expander, it could also control the rotation speed by adjusting the excitation current of the dynamometer. The accuracies of the temperature sensors, pressure sensors, flow meter, rotation speed and torque are $\pm 0.1 \mathrm{~K}, \pm 0.5 \%$ full scale, $\pm 1 \%$ full scale, $\pm 1 \mathrm{rpm}$ and $\pm 0.3 \%$ full scale as shown in Table 2 . The isentropic efficiency is

Table 2

Accuracy of the measurement system.

\begin{tabular}{lll}
\hline $\begin{array}{l}\text { Measured } \\
\text { parameters }\end{array}$ & Facility/sensor & Accuracy \\
\hline Temperature & PT100 thermal resistance detector & $\pm 0.1 \mathrm{~K}$ \\
Pressure & Huba pressure transducer & $\pm 0.3 \%$ \\
Air mass flow & Yokagawa vortex flow meter & $\pm 1 \%$ \\
Rotation speed & Chengbang DW25 electric eddy & $\pm 1 \mathrm{rpm}$ \\
Torque & dynamometer & $\pm 0.3 \%$ \\
Isentropic efficiency & & $0.56 \%$ \\
\hline
\end{tabular}

calculated by the measured pressure, temperature, flowrate and shaft power. And its accuracy is $0.56 \%$ which is calculated based on the variance analysis method.

During the experiment, the dynamometer is switched on and the rotation speed is set to be a certain value. The switch valve is opened and the solenoid valve is switched on. By adjusting the regulator, the compressed air from the cylinder is released to the scroll expander with a required pressure. All measured parameters from the on-site sensors are acquired by the data acquisition system (DAQ). When finishing the experiment, the switch valve is closed, then switching off the electricity supply to solenoid, dynamometer and DAQ. The regulator is closed at last.

\subsection{Thermodynamic modelling of the scroll expander}

\subsubsection{Volumetric equations}

The working chamber volume is both determined by fixed and orbiting scrolls' profiles. The chamber volume could be calculated by the following equation [8].

$V=\pi P_{t}\left(P_{t}-2 t\right) H_{s}\left(1+\frac{\theta}{\pi}\right)$

where $V$ is the chamber volume, $P_{t}$ the scroll pitch, $t$ thickness of the scroll vane, $H_{s}$ height of the scroll vane, $\theta$ shaft angle.

The differential of the volume to the shaft rotation angle is expressed as:

$\frac{d V}{d \theta}=P_{t}\left(P_{t}-2 t\right) H_{s}$

\subsubsection{Ideal-gas state equations}

The scroll expander is driven by the compressed air and the air is regarded as ideal gas. The ideal-gas law could be used in the process of modelling.

$p V=m R T$

where $p$ is pressure, $m$ air mass in the chamber, $R$ gas constant, $T$ temperature, respectively.

Other thermodynamic equations used in the modelling are shown below:

$$
\left\{\begin{array}{l}
U=m c_{V} T \\
h=c_{p} T \\
R=c_{p}-c_{V} \\
k=c_{p} / c_{V} \\
d W=p d V
\end{array}\right.
$$

where $U$ is the internal energy of the gas flow, $c_{p}$ constant pressure specific heat, $c_{v}$ constant volume specific heat, $R$ gas constant, $h$ specific enthalpy, $k$ ratio of $c_{p}$ and $c_{v}, W$ expansion power.

\subsubsection{Mass balance equations}

A chamber is taken as the control volume (the $j$ th chamber). There are gas leakages from the upper chamber to the next chamber through the scroll flank and radial sections. The mass conservation of the control volume can be expressed as follows [20,21]:

$\frac{d m}{d \theta}=\frac{d m_{\text {ini }}}{d \theta}-\frac{d m_{\text {outi }}}{d \theta}$

where $m$ is the gas mass in the control volume, $m_{\text {in }}$ leakage mass from the upper chamber and $m_{\text {out }}$ the mass leakage to the next one.

\subsubsection{Energy balance equations}

Based on the energy conservation, the energy balance of the control volume is expressed as follows where the kinetic and potential energy of the flow is neglected [1]. 
$\frac{d U}{d t}=\frac{d Q}{d t}-\frac{d W}{d t}+h_{\text {ini }} \frac{d m_{\text {ini }}}{d t}-h_{\text {outi }} \frac{d m_{\text {outi }}}{d t}$

where $\theta=\omega t, U=m C_{v} T$, then the equation could be transformed into

$\frac{d T}{d \theta}=\frac{1}{m C_{v}}\left[\frac{d Q}{d \theta}-\frac{d W}{d \theta}+h_{\text {in }} \frac{d m_{\text {in }}}{d \theta}-h_{\text {out }} \frac{d m_{\text {out }}}{d \theta}-u \frac{d m}{d \theta}\right]$

where $c_{v}$ is constant volume specific heat, $Q$ the heat transfer through the walls of the control volume, $W$ the output power of the expander, $h_{\text {in }}$ and $h_{\text {out }}$ the inlet and outlet specific enthalpies of the control volume, $u$ internal energy of the control mass.

\subsubsection{Leakage equations}

As discussed above, there are two types of leakage: flank leakage and radial leakage, respectively. The leakage mass can be simulated by the transient flow model going through a narrow channel $[1,3]$.

The channel flow is assumed to be steady and adiabatic with ideal gas, and the potential difference before and after the channel is neglected. The velocity after the channel is calculated from the energy conservation equation.

$u_{I I}=\sqrt{2\left(h_{I}-h_{I I}\right)}$

where the $h_{I}$ and $h_{I I}$ are the specific enthalpies before and after the channel, and subscripts I and II represent the channel inlet and outlet.

The mass flow is expressed as

$\frac{d m}{d t}=\rho_{I I} A u_{I I}$

where $\rho_{I I}$ is the air density after the channel, $A$ the channel area.

Combining Eqs. (8) and (9), the flowrate through the channel can be expressed as shown below.

$$
\begin{aligned}
& \frac{d m}{d t}=\rho_{I I} A \sqrt{2\left(h_{I}-h_{I I}\right)}=\rho_{I I} A \sqrt{2 C_{p}\left(T_{I}-T_{I I}\right)}=\rho_{I I} A\left(2 \frac{\kappa R}{\kappa-1} T_{I}\left(1-\frac{T_{I I}}{T_{I}}\right)\right)^{\frac{1}{2}} \\
& =A \sqrt{2 P_{I} \rho_{I}} \sqrt{\frac{\kappa}{\kappa-1}\left(\left(\frac{P_{I I}}{P_{I}}\right)^{\frac{2}{\kappa}}-\left(\frac{P_{I I}}{P_{I}}\right)^{\frac{\kappa+1}{\kappa}}\right)}=A \sqrt{2 P_{I} \rho_{I}} \psi
\end{aligned}
$$

where $\kappa$ is the specific heat ratio, $R$ gas constant, $P$ gas pressure.

Take the parameters of the flank and radial clearances and ration speed into Eq. (10), the mass flow leakages could be calculated by the following two equations.

$\frac{d m_{a, j}}{d \theta}=f_{a} \frac{C_{a} L_{a, j}(\theta)}{\omega}\left(\sqrt{2 p_{j}(\theta) * \rho_{j}(\theta)}\right) \psi$

$\frac{d m_{r, j}}{d \theta}=f_{r} \frac{2 C_{r} H_{s}}{\omega}\left(\sqrt{2 p_{j}(\theta) * \rho_{j}(\theta)}\right) \psi$

where $f$ is the gas flow coefficient and it equals 1 in the simulation $[1,3], C$ the clearance of the leakage section, $L$ the length of the leakage channel, $\omega$ the ration angle speed. $\psi$ is the flow function based on the gas flow state, which could be calculated by one of the following two equations. The subscript $j$ stands for the $j$ th chamber, $a$ radial leakage, $r$ the flank leakage.

When $\frac{p_{j+1}(\theta)}{p_{j}(\theta)} \geqslant\left(\frac{2}{k+1}\right)^{\frac{k}{k-1}}$, it is subsonic flow and then,

$\psi=\sqrt{\frac{k}{k-1}\left[\left(\frac{p_{j+1}(\theta)}{p_{j}(\theta)}\right)^{\frac{2}{k}}-\left(\frac{p_{j+1}(\theta)}{p_{j}(\theta)}\right)^{\frac{k+1}{k}}\right]}$

When $\frac{p_{j+1}(\theta)}{p_{j}(\theta)}<\left(\frac{2}{k+1}\right)^{\frac{k}{k-1}}$, it is supersonic flow and then, $\psi=\left(\frac{2}{k+1}\right)^{\frac{1}{k-1}} \sqrt{\frac{k}{k+1}}$

The leakage length from $j$ th to $(j+1)$ th chamber is given as below [21].

$L_{a, j}(\theta)=P_{t}(2 \pi j+\theta)$

where $P_{t}$ is the scroll pitch, $j$ is in the range of $0 \leqslant j \leqslant N-1$.

\subsubsection{Heat transfer equations}

The heat transfer happens in two ways: heat conduction and heat convection, respectively. The heat through the boundary of the control volume is presented as below [22].

$\frac{d Q}{d \theta}=\frac{K S \Delta T}{\omega}$

$\frac{1}{K}=\frac{1}{\alpha_{1}}+\frac{t}{\lambda}+\frac{1}{\alpha_{2}}$

where $K$ is the heat transfer coefficient, $\alpha$ heat convection coefficient, $\lambda$ heat conductivity, $S$ the heat transfer area in radial direction, its projection length could be regarded as the radial leakage length. Thus,

$S=L_{a, j}(\theta) \cdot H_{S}$

The coefficient of heat convection is calculated by the following equation which is taken from the Dittus-Boelter equation of nozzle turbulence flow $[22,23]$.

$\alpha=0.023 \frac{\lambda}{D}\left(\frac{u_{h} D}{v}\right)^{0.8} \operatorname{Pr}^{n}$

where $D$ is the characteristic size, $\operatorname{Pr}$ Prandtl number, $v$ dynamic viscosity. When the wall is to heat up the control volume, $n$ equals 0.4 , otherwise $n$ equals 0.3 .

\subsubsection{Power output}

The shaft power output of the expander is calculated by the following equation [1].

$P W=\eta_{m} \frac{n}{120} \sum\left(V_{i+1}+V_{i}\right)\left(p_{i+1}-p_{i}\right)$

where $n$ is the rotation speed, $\eta_{m}$ mechanical efficiency, subscript $i$ element time of the calculation.

\subsubsection{Volumetric and isentropic efficiencies}

The volumetric efficiency is used to evaluate the leakage effect, which is the ratio of the ideal mass flow to the real the mass flow.

$\eta_{v}=\frac{q_{m i}}{q_{m a}}$

where $\eta_{v}$ is the volumetric efficiency, $q_{m i}$ the ideal mass flow, $q_{m a}$ the real mass flow. The ideal mass flow was calculated by the first chamber under the inlet conditions without consideration of the leakages.

Table 3

Parameters of the studied scroll expander.

\begin{tabular}{lll}
\hline Item & Parameter & Value \\
\hline Radius of the basic circle & $a(\mathrm{~m})$ & $4.138 \times 10^{-3}$ \\
Initial angle of the involute & $\gamma\left(^{\circ}\right)$ & 31.154 \\
Expansion starting angle & $\theta_{s}\left(^{\circ}\right)$ & 131.015 \\
Expansion ending angle & $\theta_{d}\left(^{\circ}\right)$ & 720 \\
Scroll vane height & $h(\mathrm{~m})$ & $4.65 \times 10^{-2}$ \\
Distance between the two basic circles' centers & $r(\mathrm{~m})$ & $8.5 \times 10^{-3}$ \\
Radial clearance & $C_{r}(\mathrm{~m})$ & $6.0 \times 10^{-5}$ \\
Axial clearance & $C_{a}(\mathrm{~m})$ & $6.0 \times 10^{-5}$
\end{tabular}


The isentropic efficiency of the scroll expander is calculate by the following equation,

$\eta_{\text {am }}=\frac{P W}{P_{\text {air }}}$

where $P W$ is the shaft power, $P_{\text {air }}$ the ideal power generation of the compressed air through an isentropic expansion process.

\section{Results and discussion}

The parameters of the studied scroll expander are given in Table 3. The scroll vanes are produced from a circle involute.

Both experiment (exp) and simulation (sim) results under different inlet pressure are shown in Fig. 6. One could see that the simulation results agree well with the experimental results. The simulation flowrate error is less than $6 \%$, and the power error is less than $15 \%$. The flowrate is in the range of $63.2-161.6 \mathrm{~kg} / \mathrm{h}$ and the power output is in the range of $0.24-1.2 \mathrm{~kW}$ according to the experimental results. Both flowrate and power output increase with the rotation speed increment under different inlet pressures (0.4 MPa, $0.5 \mathrm{MPa}$ and $0.7 \mathrm{MPa}$ ). This is because there would be a strong leakage effect from the upper chamber to the next when the rotation speed is low, which does not expand sufficiently in the upper chamber and also disturbs the air expansion ability compared with the ideal non-leakage state. It also reveals that flowrate and power increase when the inlet pressure increases. Take the case at $1000 \mathrm{rpm}$ as an example, the flowrate and power output are $95 \mathrm{~kg} / \mathrm{h}$ and $0.71 \mathrm{~kW}$ under inlet pressure of $0.4 \mathrm{MPa}$, $102.8 \mathrm{~kg} / \mathrm{h}$ and $0.85 \mathrm{~kW}$ under inlet pressure $0.5 \mathrm{MPa}$, and $161.6 \mathrm{~kg} / \mathrm{h}$ and $1.2 \mathrm{~kW}$ under inlet pressure $0.7 \mathrm{MPa}$.

Fig. 7 shows the volumetric and isentropic efficiencies of the scroll expander under inlet pressure 0.5 MPa. One could see that both efficiencies increase along with the rotation speed. They are $44.2 \%$ and $30.5 \%$ at $1200 \mathrm{rpm}$, respectively. The main reason is that when the speed increased, the leakage time for the same amount of air flow reduces. Thus, the volumetric and isentropic efficiencies increase.

Figs. 8-10 show the simulation results of scroll expander working volume, the air mass of the working volume and the pressure change of the working volume with the rotation angle when the inlet pressure is $0.5 \mathrm{MPa}$ and rotation speed is $1000 \mathrm{rpm}$. It shows that the working volume increases monotonically with rotation angle in Fig. 8. Fig. 9 shows the air mass in the control volume at different rotation angle. It can be divided into three phases regarding the curve shape in Fig. 9, they are first chamber with high pressure, second chamber, and the exhaust chamber. One could see that the air mass decreases sharply at the beginning (in the first chamber), then starts increasing at around $230^{\circ}$ rotation angle, and it tends to decrease again at around $550^{\circ}$ rotation angle until

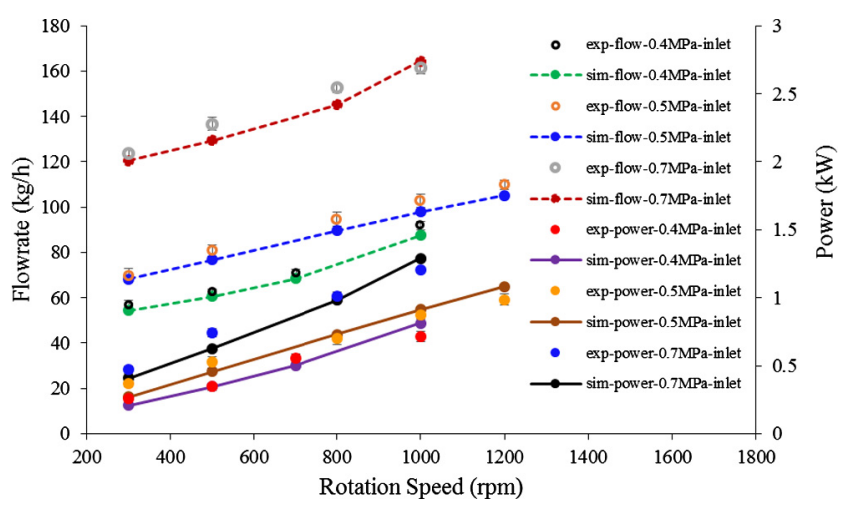

Fig. 6. Flowrate and power output as a function of the rotation speed.

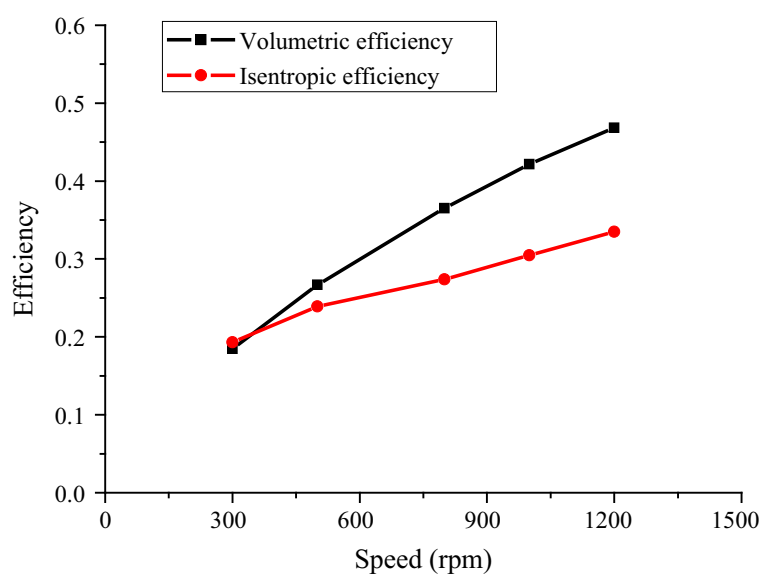

Fig. 7. volumetric and isentropic efficiencies as a function of rotation speed (inlet pressure $0.5 \mathrm{MPa}$ ).

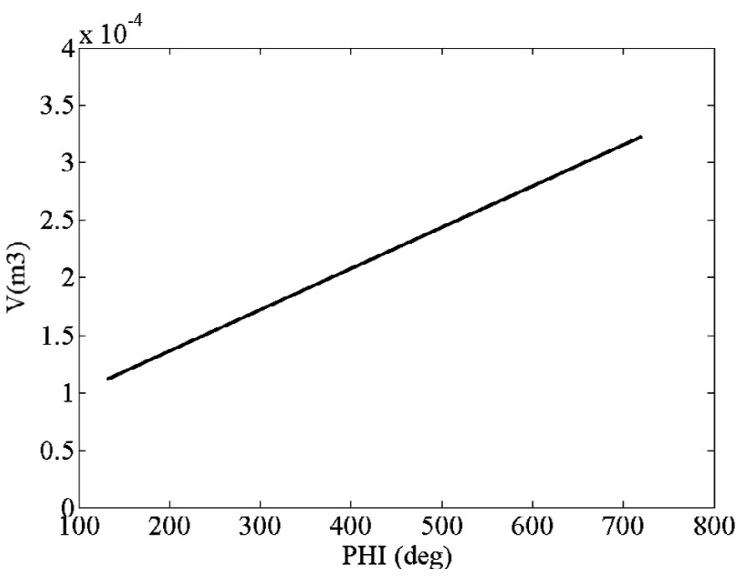

Fig. 8. The working volume as a function of the rotation angle.

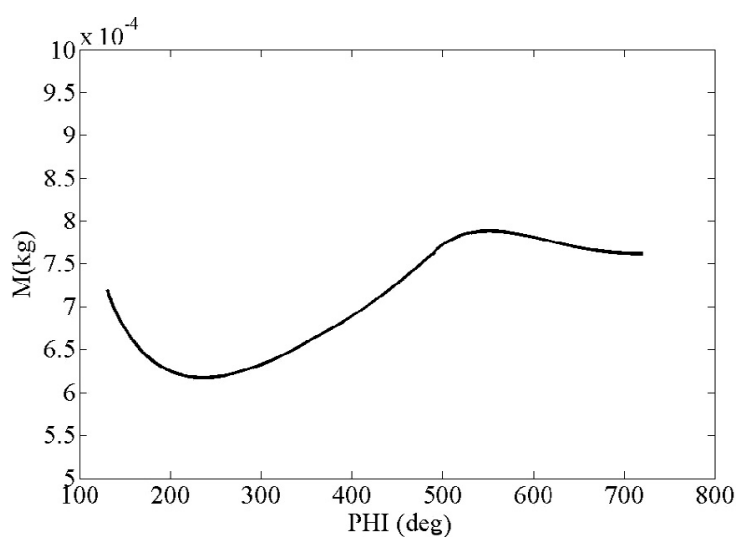

Fig. 9. The working volume air mass as a function of the rotation angle.

the expansion process finishes. This phenomenon can be explained with Fig. 10. In Fig. 10, the pressure in the chamber is shown as a function of the rotation angle. In the first chamber, the air pressure is high, and the pressure difference between the first chamber and the second chamber is large causing a strong leakage through radial and flank clearances. A relatively large amount of air is leaked to the second chamber, thus the air mass increased and its pressure decreases slowly in the next chamber during the expansion process. Take the second chamber as the object one, it 


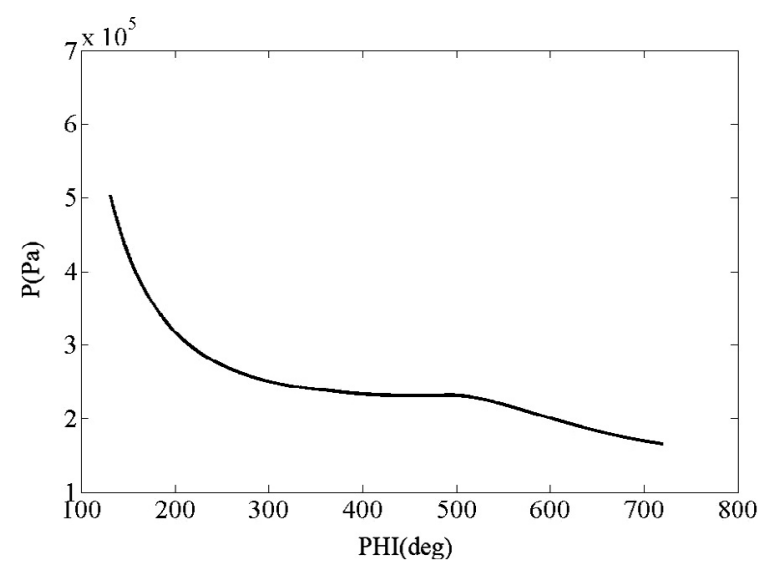

Fig. 10. The working volume pressure as a function of the rotation angle.

receives the leaked air from the upper one and also leaks air to the next one. But the pressure difference between this chamber and the exhaust one is lower, thus the air leaked out is not as much as the air leaked into this chamber. It has a little effect of the leakage at the end of the expansion process because of the small pressure difference between the chamber and the ambience. Its mass and pressure tend to level off.

From Fig. 10, one could notice that when the expander starts discharging, the outlet pressure is somewhat higher than the ambient pressure, which indicates the compressed air is not expanding completely inside the expander. The pressure match of a certain scroll expander would be discussed in the next section.

\section{Optimization analysis}

\subsection{Pressure ratio optimization analysis}

Generally, there are three types of expansion process depending on the inlet air pressure once the expander is designed. They are (i) normal expansion, of which the outlet air pressure is almost similar to the ambient pressure (Fig. 11(a)); (ii) deficient expansion, of which the discharging air pressure is higher than the ambient pressure, thus the energy of the compressed air is not fully extracted (Fig. 11(b)); (iii) over expansion, of which the inlet pressure is smaller than a certain value then the final outlet air pressure is below the ambient pressure, thus it would cause reverse flow during discharging process (Fig. 11(c)). In Fig. $11, \varepsilon^{*}$ is the real pressure ratio, $\varepsilon$ the designed pressure ratio, $P_{h}$ the inlet pressure, $P_{a}$ the ambience pressure, $P_{x}$ expansion end pressure, $A-B$ gas inlet process, $B-C$ expansion process, $C-D-E$ exhaust process. The pressure ratio is regarded as the inlet pressure divided by the ambience pressure.
Based on the illustration in Fig. 11, the ideal expansion efficiency could be expressed as Eq. (23). The denominator is the maximum energy in the compressed air, and the numerator is the energy extracted from the compressed air through the ideal expansion process.

$\eta_{s}=\frac{p_{h} V_{B}+m_{h}\left(u_{B}-u_{C}\right)-p_{a} V_{C}}{m_{h}\left(h_{B}-h_{D^{\prime}}\right)}$

where $m_{h}$ is the inlet air quality in the first chamber of the studied expander without air leakage, $u_{B}$ the specific internal energy of the inlet air, $u_{C}$ the specific internal energy of the air after expansion, $p_{a}$ the ambient pressure, $h_{D^{\prime}}$ the specific enthalpy of the air at the ambient pressure of $p_{a}$.

According to Eq. (23), the thermal efficiency of the ideal expansion through a scroll expander can be simulated as shown in Fig. 12. One could see that once the scroll expander is designed, there is a certain pressure ratio that makes the expander work at a high efficiency level. Regarding the studied expander, the optimal pressure ratio is around 4 as shown in Fig. 12.

Based on the above analysis, the working performance of the studied scroll expander is examined under various inlet pressures. The pressure ratio is in the range of $1.5-10$, and rotation speed in the range of 500-5000 rpm. Fig. 13 shows the flowrate as a function of pressure ratio under various rotation speeds. One could see that the flowrate increases monotonically with the pressure ratio. The higher the speed is, the more flowrate it has.

Fig. 14 shows the power output as a function of the pressure ratio under various rotation speeds. Under the studied conditions, the power output is in a large range of several watts to almost $10 \mathrm{~kW}$. The power output increases with pressure ratio, and the rotation speed as well. It also can be seen that the curve slope changed obviously when the pressure ratio is about 3.5-4. That is because below that range it is over expansion process, the power output grows quickly with the inlet pressure. It reaches the deficient expansion process above that range, and the internal energy of compressed air is not fully extracted. Fig. 15 shows the specific energy output as a function of the pressure ratio under various rotation speeds. When the pressure ratio is less than 4 roughly, the specific energy rises with the pressure ratio, which means more energy is extracted from the compressed air. The curves are almost levelled off when the pressure ratio is larger than 4 . Although the fluid's internal energy, flowrate and power output increase, the specific energy does not increase with the pressure ratio. The figure also shows that the flow produces more specific energy with a higher rotation speed at the same pressure ratio.

Fig. 16 shows the volumetric efficiency as a function of the pressure ratio under various rotation speeds. At a certain speed (less than $3000 \mathrm{rpm}$ in Fig. 16), the volumetric efficiency decreases slightly when expander is under deficient expansion, and then it levels off with the pressure ratio. Also shown in Fig. 16, the higher

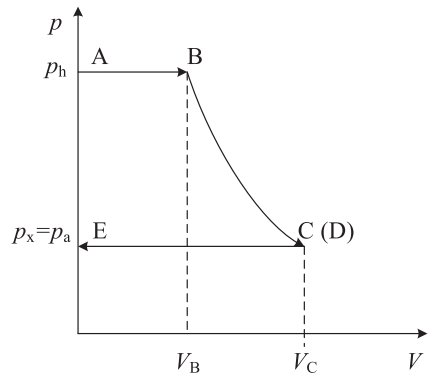

(a) $\varepsilon^{*}=\varepsilon$

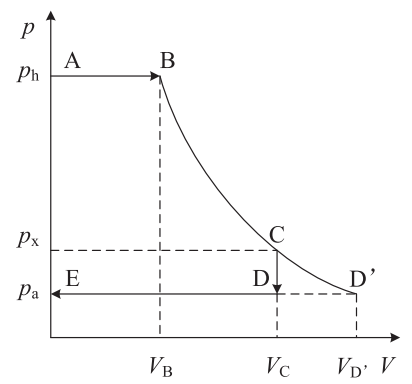

(b) $\varepsilon^{*}>\varepsilon$

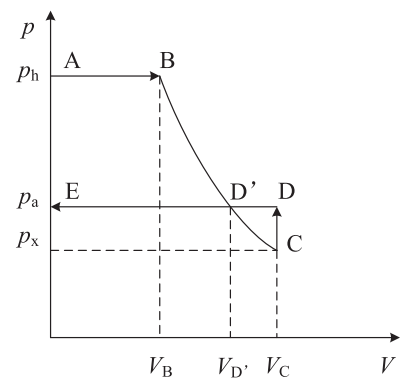

(c) $\varepsilon^{*}<\varepsilon$

Fig. 11. Three types of expansion process. 


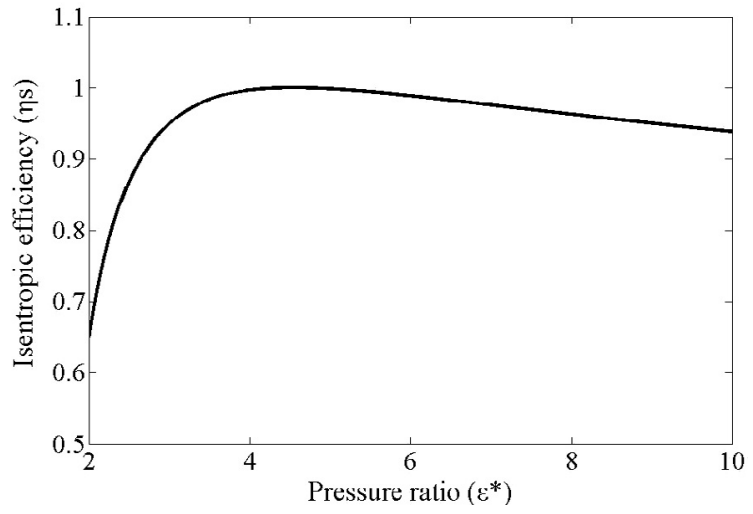

Fig. 12. Isentropic efficiency of ideal expansion process under various pressure ratio.

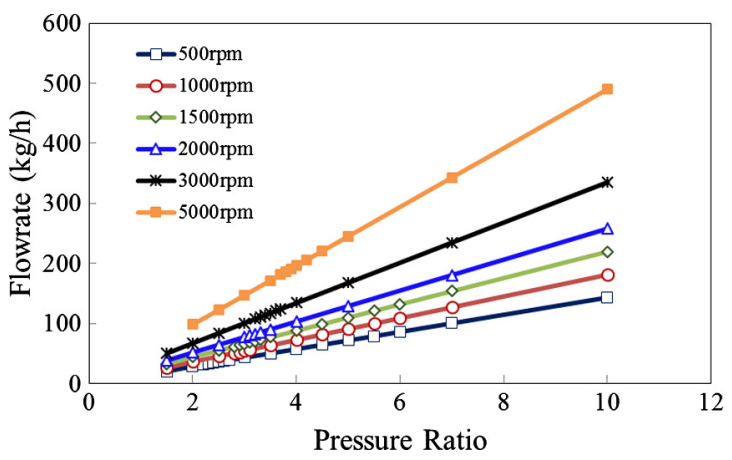

Fig. 13. Flowrate as a function of pressure ratio.

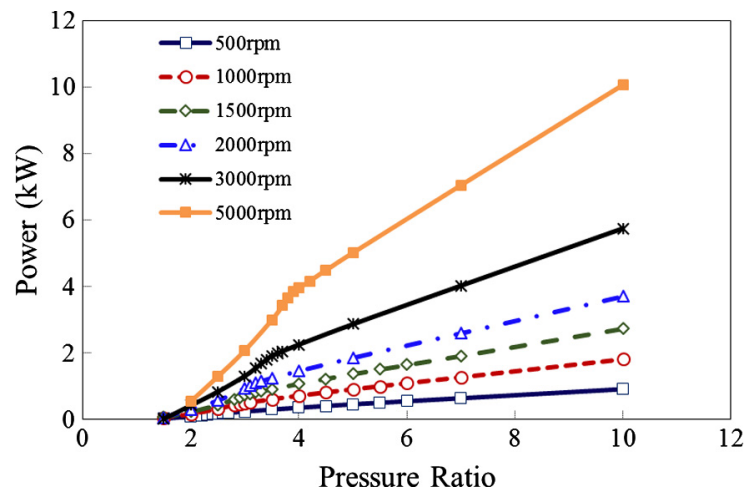

Fig. 14. Power output as a function of pressure ratio.

speed allows relatively less leakage, thus, its volumetric efficiency is relatively high.

Fig. 17 shows the isentropic efficiency as a function of the pressure ratio under various rotation speeds. Similar to Fig. 12, at each rotation speed, the efficiency increases at first to a peak point in the pressure ratio range of 3-4. It tends to decrease when the pressure ratio continues increasing. The expander works at around "normal expansion" state as the pressure ratio within the range of 3-4. One could see that the peak point moves to the larger pressure ratio with the rotation speed. The reason is that at low speed, there exists strong leakage effect, and relatively more air leaks to the next chamber, which also joins the air in that chamber to expand and generate some power. As shown in Figs. 9 and 10, this can also make up the ideal pressure decrease in that chamber compared with that of no leakage receiving. In Fig. 17, it also reveals

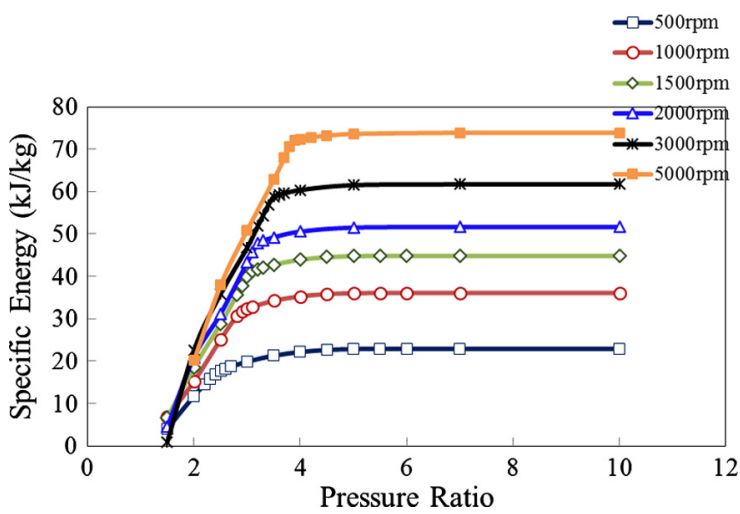

Fig. 15. Specific energy output as a function of pressure ratio.

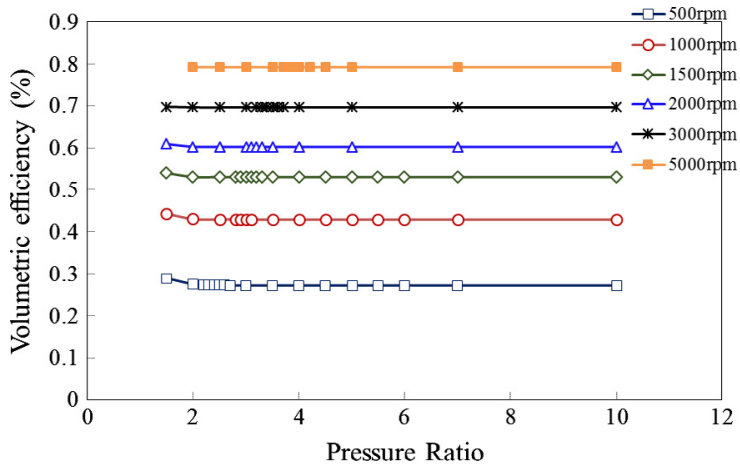

Fig. 16. Volumetric efficiency as a function of pressure ratio.

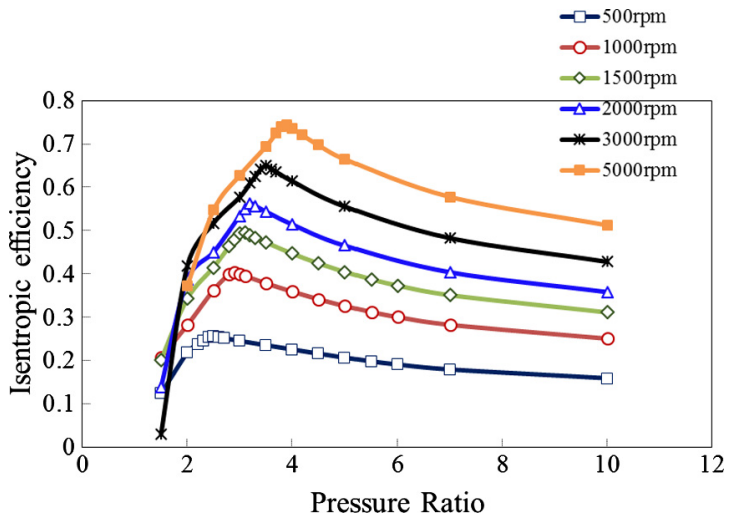

Fig. 17. Isentropic efficiency as a function of the pressure ratio.

the expander works at a higher isentropic efficiency under a higher rotation speed when the pressure ratio is around the optimal value or above it.

\subsection{Inlet temperature effect}

The scroll expander is usually integrated into the low and moderate grade energy utilization (up to around $350^{\circ} \mathrm{C}$ ). In this section, the air inlet temperature is considered to reveal its effect on the expander's performance, and the studied temperature range is from $300 \mathrm{~K}$ to $800 \mathrm{~K}$ with the rotation speed of $1000-3000 \mathrm{rpm}$. The optimal pressure ratio is in the range of 3-4 as indicated in Fig. 17. In this section, the pressure ratio is set to be 4 in order to avoid any over expansion. 


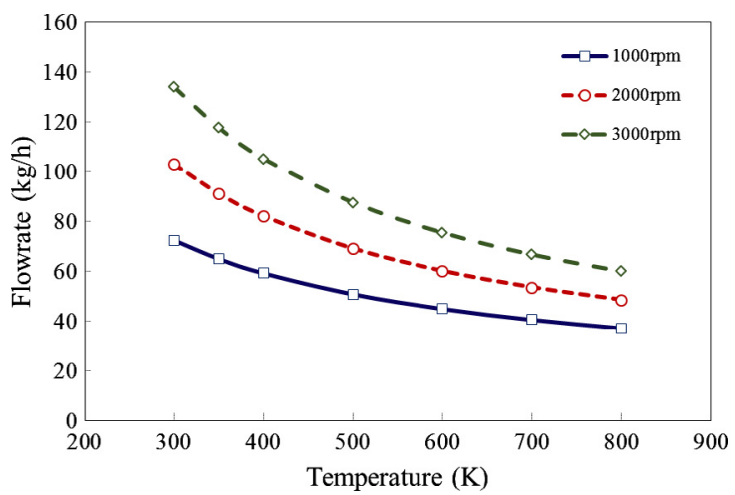

Fig. 18. Flowrate as a function of inlet temperature.

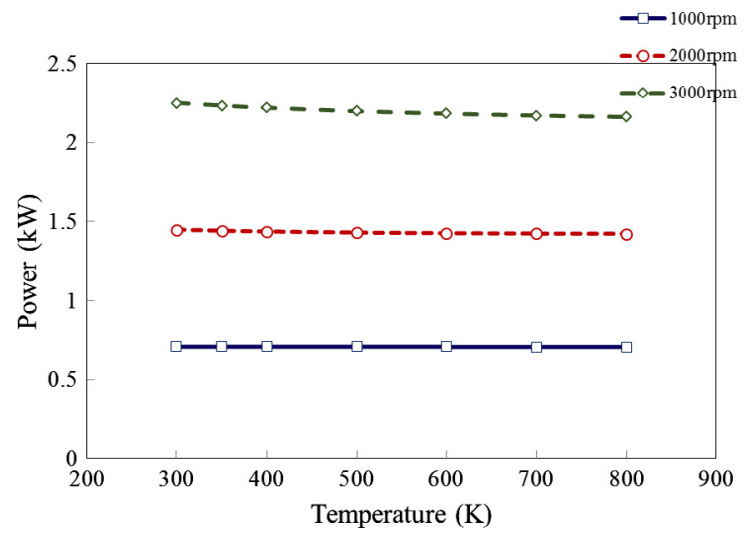

Fig. 19. Power output as a function of inlet temperature.

Fig. 18 shows the flowrate as a function of the inlet temperature with different rotation speed. It shows that the flowrate is in the range of $37.2-134.1 \mathrm{~kg} / \mathrm{h}$. The flowrate decreases with the temperature increment at a certain speed, and the flowrate also increases with the rotation speed at the same inlet temperature. The reason is that the air density decreases when increasing the temperature. Thus the air mass for each cycle of the volumetric expander is reduced, which results in less flowrate.

Fig. 19 shows the power output as a function of the inlet temperature with different rotation speeds. It can be seen that the power output is in the range of $0.71-2.25 \mathrm{~kW}$, and with a certain speed the power output is almost stable, which means the air inlet temperature generates almost no effect on the power output for a volumetric expander. As the power output is almost stable and the flowrate decreases, the specific power increases along with the inlet temperature increase as shown in Fig. 20.

Fig. 21 shows the volumetric efficiency as a function of the inlet temperature with different rotation speeds. The efficiency decreases monotonically when increasing temperature with a same rotation speed. And the efficiency increases with the speed at a same temperature. From Eqs. (11) and (12), one can see that when the density decreases, the air leakage decreases as well, which is proportional to the square root of the density, while the air mass flowrate is proportional to the density itself. Thus the ratio of the air leakage to the mass flowrate increases, which results in the volumetric efficiency reduction.

Fig. 22 shows the isentropic efficiency as a function of the inlet temperature with different rotation speeds. One could see that the efficiency decreases from $61.4 \%$ to $48.6 \%$ at $3000 \mathrm{rpm}$ and $35.9 \%$ to $25.8 \%$ at $1000 \mathrm{rpm}$ when the temperature rises from $300 \mathrm{~K}$ to $800 \mathrm{~K}$, although theoretically the expander isentropic efficiency is

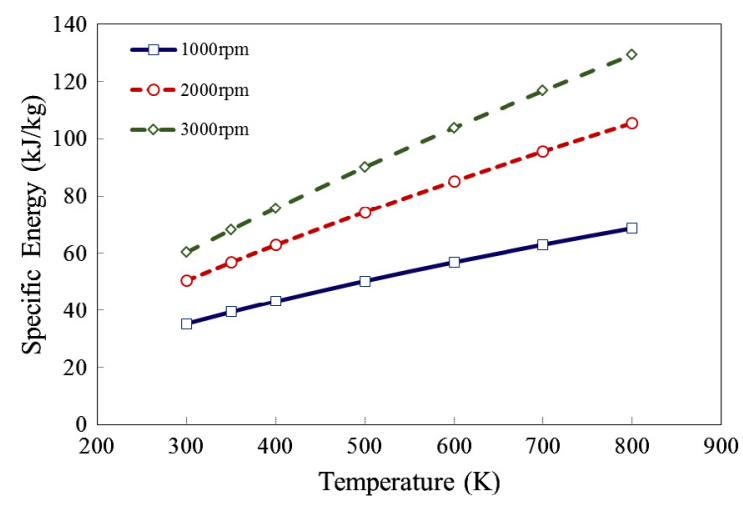

Fig. 20. Specific energy as a function of inlet temperature.

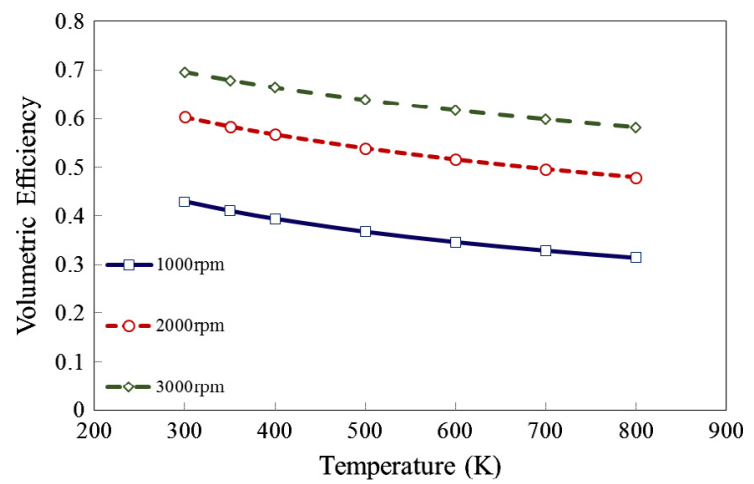

Fig. 21. Volumetric efficiency as a function of inlet temperature.

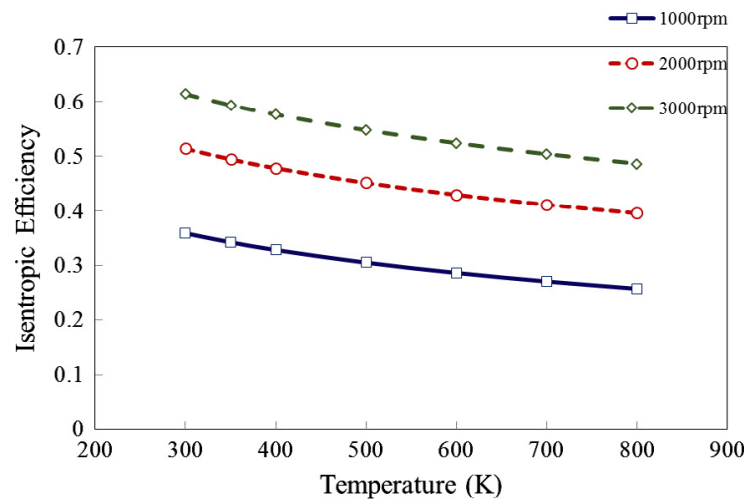

Fig. 22. Isentropic efficiency as a function of inlet temperature.

almost constant with various inlet temperature as revealed in Ref. [24]. It is mainly because of the volumetric efficiency reduction as shown in Fig. 21. The isentropic efficiency is greater under the same inlet temperature with a higher rotation speed.

\subsection{Clearance effect}

In Section 5.1, we can see that the air leakage between two adjacent chambers has a significant impact on the expander performance. In this section, various clearance sizes are introduced to examine the effect.

As indicated in Section 5.1, the pressure ratio is also set to 4 in order to avoid any over expansion. It is recommended that the clearance size is around $0.02 \mathrm{~mm}$ [22]. In this study, both radial 


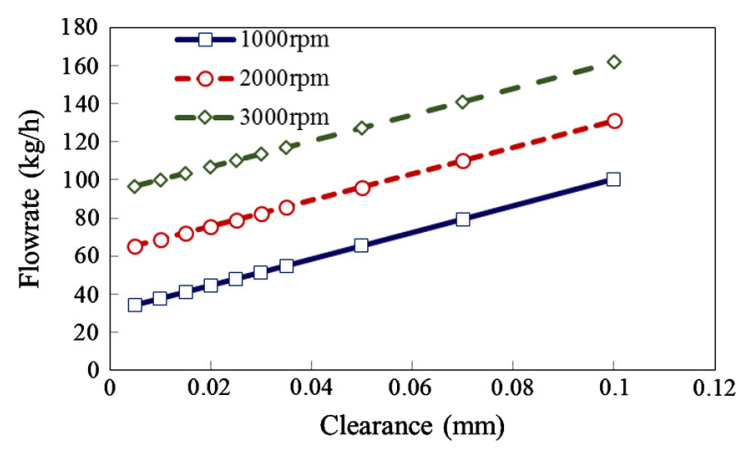

Fig. 23. Flowrate as a function of the clearance.

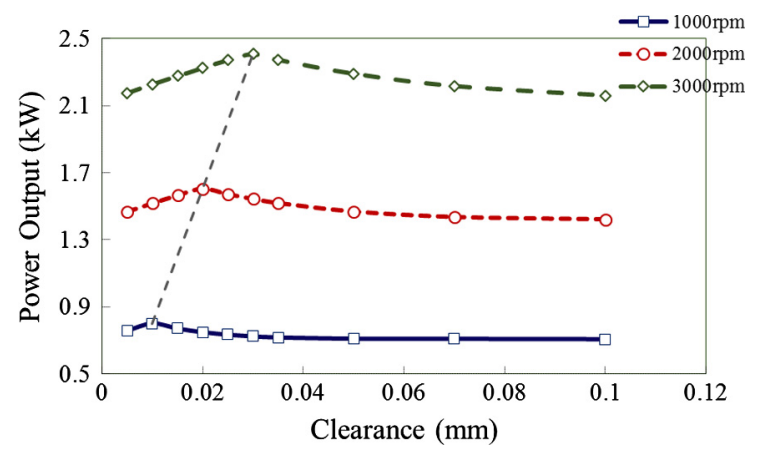

Fig. 24. Power output as a function of the clearance.

and flank clearances are chosen to be among $0.005-0.1 \mathrm{~mm}$ with the rotation speed of 1000-3000 rpm.

Fig. 23 shows the flowrate as a function of the clearance with different rotation speed. It shows that the flowrate is in the range of $34.5-161.7 \mathrm{~kg} / \mathrm{h}$. The flowrate increases with the clearance at a certain speed, and the increment is about $65 \mathrm{~kg} / \mathrm{h}$ when the radial and flank clearance increases from 0.005 to $0.1 \mathrm{~mm}$. The flowrate also increases with the rotation speed at the same clearance size.

Fig. 24 shows the power output as a function of the clearance with different rotation speeds. It can be seen that the power output is in the range of $0.71-2.41 \mathrm{~kW}$, and with a certain speed the power output increases slightly at first and decreases, and then it tends to level off. A dash line is illustrated in Fig. 24 to connect the peak power output point of the three curves. It indicates the clearance size increases for the peak power output when the rotation speed increases. The expander generates more power with a higher speed at the same clearance. As discussed in Fig. 17, when the clearance increases, more leakage is going into the next chamber, and it also induces more air to the expander raising the flowrate as shown in Fig. 23. The leaked air also helps generate power in the next chamber. However, the specific energy of the flow decreases as shown in Fig. 25. It declines slightly when the clearance is around small values, then it drops much. That is because when the clearance becomes larger, the more leakage flow would disturb the normal flow causing specific energy generation abatement.

Fig. 26 shows the volumetric efficiency as a function of the clearance with different rotation speeds. The efficiency decreases monotonically from $90.2 \%$ to $30.9 \%$ with the clearance size. And the efficiency increases with the speed at a same clearance. Fig. 27 shows the isentropic efficiency as a function of the clearance with different rotation speeds. One could see that the efficiency decreases from $80 \%$ to $23 \%$ at $1000 \mathrm{rpm}$ and $82.3 \%$ to $48.9 \%$ at $3000 \mathrm{rpm}$ when the clearance rises from $0.005 \mathrm{~mm}$ to $0.1 \mathrm{~mm}$. The efficiency is greater under the same clearance with a higher rotation speed.

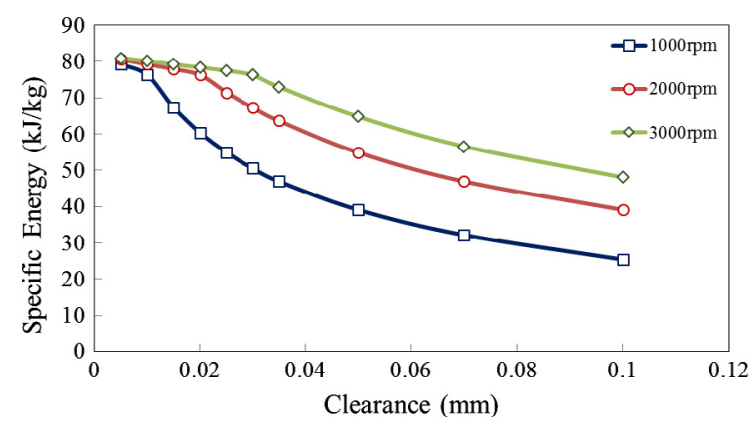

Fig. 25. Specific energy output as a function of the clearance.

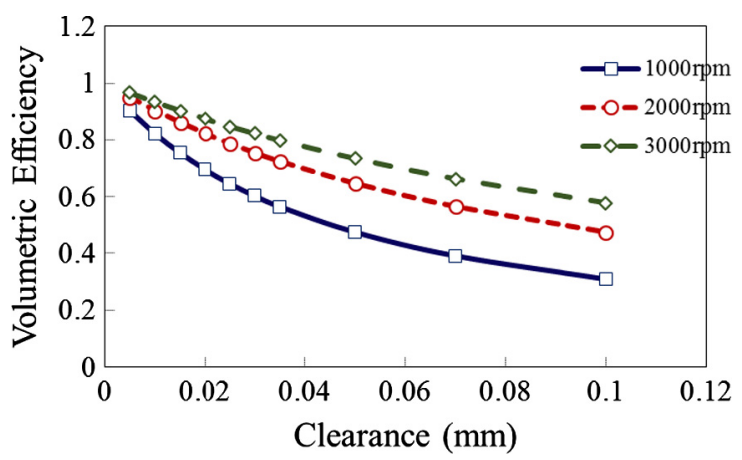

Fig. 26. Volumetric efficiency as a function of the clearance.

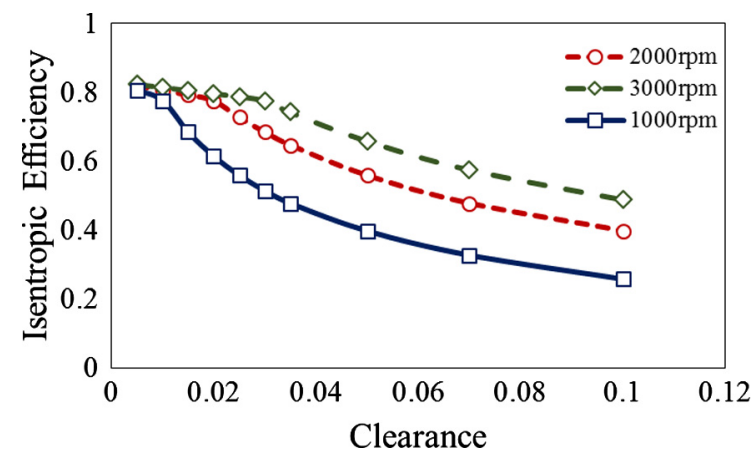

Fig. 27. Isentropic efficiency as a function of the clearance.

And in order to get a high isentropic efficiency, it would require as small clearance as possible. But taking the power output (Fig. 24) and manufacture convenience into consideration, it would be favourable if the clearance is no more than $0.06 \mathrm{~mm}$.

\subsection{Scroll vane height to pitch ratio effect}

The scroll vane height would influence the flow passage cut area, the chamber volume, the flank clearance, the radial clearance to the vane height ratio and the manufacture feasibility. Generally, the scroll vane height is determined by a parameter $\xi$ which refers to the ratio of vane height to scroll pitch $\left(H_{s} / P_{t}\right.$, Fig. 3). The parameter $\xi$ is usually in the range of 1-2.5 [22]. In this section, the simulation study is carried out under various $\xi$ values. It is assumed that the pitch is constant. The pressure ratio is set to be 4 , and the rotation speed is $1000 \mathrm{rpm}, 2000 \mathrm{rpm}$ and $3000 \mathrm{rpm}$.

Fig. 28 shows the flowrate as a function of height to pitch ratio $(\xi)$ at different rotation speeds. The flowrate is from 51.8 to $177.4 \mathrm{~kg} / \mathrm{h}$ under the studied conditions. It reveals that the flowrate increases monotonically with $\xi$ at a certain rotation speed, 


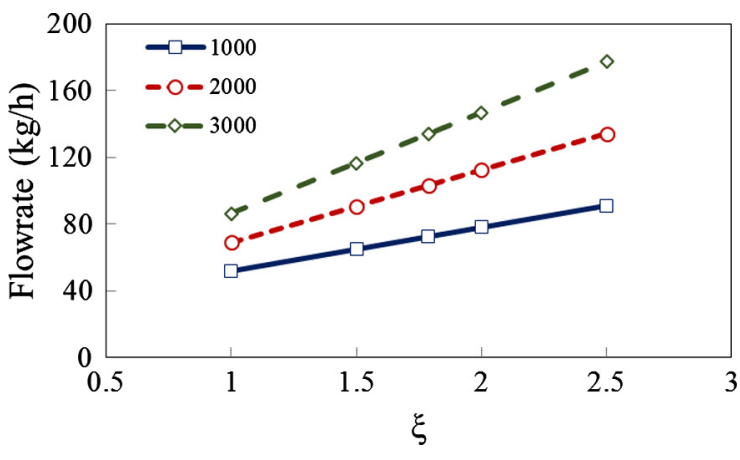

Fig. 28. Flowrate as a function of scroll vane height to pitch ratio.

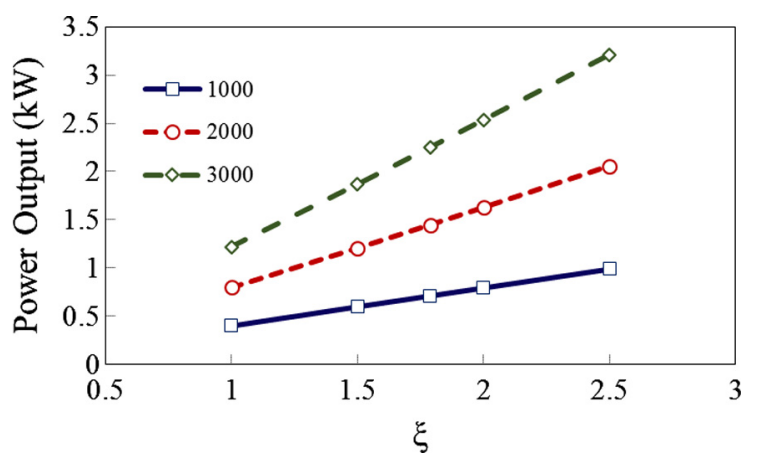

Fig. 29. Power output as a function of the scroll vane height to pitch ratio.

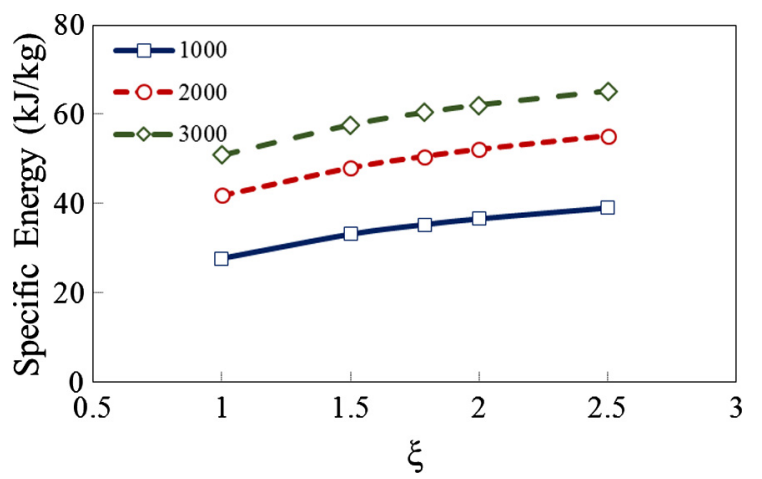

Fig. 30. Specific energy output as a function of the scroll vane height to pitch ratio.

and also with the rotation speed at a certain value of $\xi$. Fig. 29 shows the power output as a function of $\xi$ at different ration speeds. It shows a similar trend with the flowrate in Fig. 28. Fig. 30 shows the specific energy output as a function of the scroll vane height to pitch ratio, in which it also upturns with the ratio, but the increasing trend tends to level off. It is assumed that the pitch is constant. When increasing the ratio, the flow cut area and the chamber volume are increased. Hence, the flowrate increases, and the power output increase as well. Fig. 31 shows that the volumetric efficiency increases, which means relatively less air leaks to the next chamber. The compressed air could expand more sufficiently, and also less air leaks to the next chamber causing less disturbance. Thus, the specific energy output increases as shown in Fig. 30.

Fig. 31 shows the volumetric efficiency as a function of $\xi$ with different rotation speeds. Under the studied conditions, the volumetric efficiency is among $33.5 \%$ to $73.5 \%$. One can see that the volumetric efficiency increases with the value of $\xi$ at a certain speed,

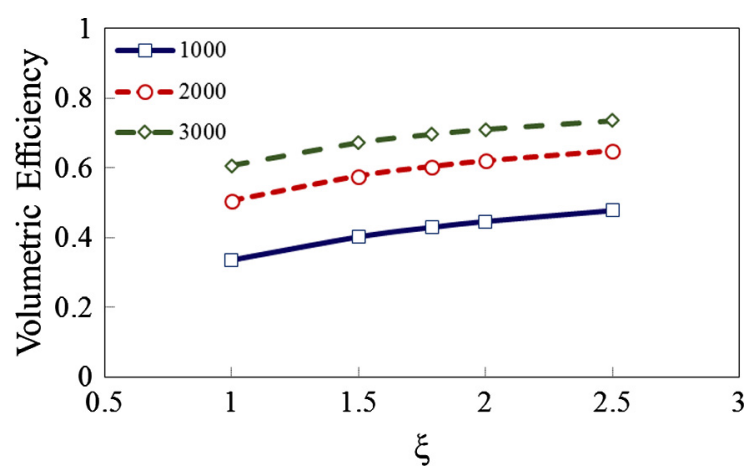

Fig. 31. Volumetric efficiency as a function of height to pitch ratio.

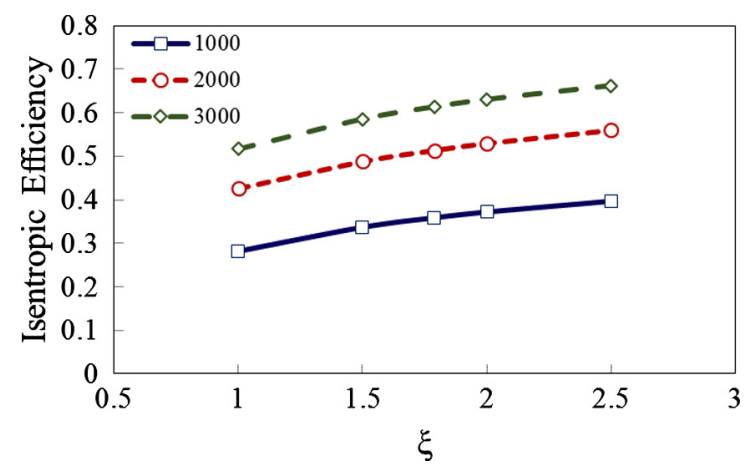

Fig. 32. Isentropic efficiency as a function of height to pitch ratio.

which reveals relatively less air leakage going through the clearances. Although the flank clearance increases with vane height, the efficiency grows as well. It can be calculated from Eqs. (11) and (12) that the radial clearance has a large leakage area, which leads to more air leakage. That means the radial leakage has a greater effect on the volumetric efficiency. When increasing the vane height, the radial clearance to the vane height ratio decreases, so that the radial leakage affects the main passage flow in a relatively less scale, which leads to the increasing volumetric efficiency. Fig. 31 also explains the increase trend of the specific energy output.

Fig. 32 shows the isentropic efficiency as a function of $\xi$ at different rotation speed. It is in the range of $28.2-66.2 \%$ under studied conditions with a similar trend of volumetric efficiency in Fig. 31. One can see that the isentropic efficiency increases with the value of $\xi$ at a certain speed. The growth rate is over $13 \%$ when $\xi$ increased from 1 to 2.5 with the same speed of the studied conditions. Since the radial leakage does not have a significant impact on the main flow, the compressed air could expand relatively closer to the ideal value. Also the next chamber will not be disturbed too much by the leakage. As a consequence, the isentropic efficiency increases along with the increase of the vane height to pitch ratio.

\section{Conclusion}

A scroll expander is studied through both experiment and simulation work and the simulated and experimental results are in a good agreement. Based on the simulation method, an optimization analysis is further conducted in respect of the working pressure ratio, air inlet temperature, clearance size and scroll vane height to pitch ratio.

It is concluded as follows: 
(1) A scroll expander model is developed and it is validated by the experiment. The modelling can be used to analyse the scroll expander performance. The expander's internal parameters as functions of the rotation angle are obtained. The flow process and its loss mechanism are elaborated.

(2) There would be an optimal pressure ratio under which the expander works with high efficiency. The optimal pressure ratio also varies in a small range with different rotation speeds. For the studied scroll expander, the optimal pressure ratio is in the range of 3-4. The flowrate and power output increase with the pressure ratio, and the volumetric efficiency almost stays stable under same speed.

(3) The temperature has almost no influence on the power output of the expander, while the flowrate decreases and the specific energy increases with the air inlet temperature increment. However, the volumetric efficiency and isentropic efficiency decrease with the temperature.

(4) The clearance size (radial and flank clearances) has a significant impact on the expander performance. When the clearance rises, the flowrate increases moronically, the power output first increases and then decreases slightly and then almost levels off, and the volumetric and isentropic efficiencies decrease. It would be favourable if the clearance is no more than $0.06 \mathrm{~mm}$.

(5) When the scroll vane height to pitch ratio grows, the flowrate and power output increase monotonically, and the volumetric and isentropic efficiency upturns in a relatively slow trend.

\section{Acknowledgements}

The authors would like to thank the following organizations for financial support of the work: National Natural Science Foundation of China (NSFC) under Grant No. 51206159, Beijing Natural Science Foundation (BJNSF) under Grant No. 3152024, Key Project of Chinese National Programs for Fundamental Research and Development (973 program) under Grant No. 2015 CB251302 and CAS Interdisciplinary Innovation Team.

\section{References}

[1] Liu G, Zhao Y, Li L, Shu P. Simulation and experiment research on wide ranging working process of scroll expander driven by compressed air. Appl Therm Eng 2010;30:2073-9.

[2] Lemort V, Quoilin S, Cuevas C, Lebrun J. Testing and modeling a scroll expander integrated into an organic Rankine cycle. Appl Therm Eng 2009;29:3094-102.
[3] Song P, Wei M, Shi L, Danish SN, Ma C. A review of scroll expanders for organic Rankine cycle systems. Appl Therm Eng 2015;75:54-64.

[4] Chu X, Zhang C, Li K, Jing Y. Dynamic modeling and efficiency analysis of compressed air energy storage system equipped with scroll compressor. Trans China Electrotech Soc 2011;26:7.

[5] Clemente S, Micheli D, Reini M, Taccani R. Energy efficiency analysis of organic Rankine cycles with scroll expanders for cogenerative applications. Appl Energy 2012;97:792-801.

[6] Qiu G, Liu H, Riffat S. Expanders for micro-CHP systems with organic Rankine cycle. Appl Therm Eng 2011;31:3301-7.

[7] Declaye S, Quoilin S, Guillaume L, Lemort V. Experimental study on an opendrive scroll expander integrated into an ORC (organic Rankine cycle) system with R245fa as working fluid. Energy 2013;55:173-83.

[8] Kim HJ, Ahn JM, Cho SO, Cho KR. Numerical simulation on scroll expandercompressor unit for $\mathrm{CO}_{2}$ trans-critical cycles. Appl Therm Eng 2008;28:1654-61.

[9] Kohsokabe H, Koyama M, Tojo K, Matsunaga M, Nakayama S. Performance characteristics of scroll expander for $\mathrm{CO}_{2}$ refrigeration cycles. In: International compressor engineering conference. p. 9. Purdue.

[10] Clemente S, Micheli D, Reini M, Taccani R. Bottoming organic Rankine cycle for a small scale gas turbine: a comparison of different solutions. Appl Energy 2013;106:355-64.

[11] Zhou N, Wang X, Chen Z, Wang Z. Experimental study on organic Rankine cycle for waste heat recovery from low-temperature flue gas. Energy 2013;55:216-25.

[12] Quoilin S, Lemort V, Lebrun J. Experimental study and modeling of an organic Rankine cycle using scroll expander. Appl Energy 2010;87:1260-8.

[13] Bao H, Wang Y, Roskilly AP. Modelling of a chemisorption refrigeration and power cogeneration system. Appl Energy 2014;119:351-62.

[14] Sun H, Luo X, Wang J. Feasibility study of a hybrid wind turbine system integration with compressed air energy storage. Appl Energy 2015;137:617-28.

[15] Chen Y, Halm NP, Groll EA, Braun JE. Mathematical modeling of scroll compressors-Part I: compression process modeling. Int $\mathrm{J}$ Refrig 2002;25:731-50.

[16] Chen Y, Halm NP, Braun JE, Groll EA. Mathematical modeling of scroll compressors-Part II: overall scroll compressor modeling. Int J Refrig 2002;25:751-64.

[17] Wang B, Li X, Shi W. A general geometrical model of scroll compressors based on discretional initial angles of involute. Int J Refrig 2005;28:958-66.

[18] Park YC, Kim Y, Cho H. Thermodynamic analysis on the performance of a variable speed scroll compressor with refrigerant injection. Int J Refrig 2002;25:1072-82.

[19] Song P, Wei M, Liu Z, Zhao B. Effects of suction port arrangements on a scroll expander for a small scale ORC system based on CFD approach. Appl Energy 2015;150:274-85.

[20] Yang X, Wang J, Zhang D. Numerical simulation of a scroll compressor used for compressed air energy storage. In: 3rd IEEE international conference on computer science and information technology (ICCSIT). IEEE; 2010. p. 262-6.

[21] Chen B, Yu Y, Feng S. Thermodynamic investigation on scroll expander. Hangzhou: School of Mechanical and Energy Engineering, Zhejiang University; 2004.

[22] Gu Z, Yu Y, Feng S. Scroll compressor and other scroll machines. Xi'an: Shanxi Science and Technology Press; 1998.

[23] Atesmen KM. Heat transfer in rotary combustion engines. J Heat Transfer 1975;97:288-93.

[24] Zhang N, Cai R. Analytical solutions and typical characteristics of part-load performances of single shaft gas turbine and its cogeneration. Energy Convers Manage 2002;43:1323-37. 